\title{
Power Quality Improvement Using Three-Phase Solar PV Integrated UPQC
}

\author{
V Nanthagopal ${ }^{1}$ | Dr. S Chitra ${ }^{2}$ \\ 1PG Scholar, Department of EEE, Government College of Technology, Coimbatore, Tamilnadu, India. \\ ${ }^{2}$ Assistant Professor, Department of EEE, Government College of Technology, Coimbatore, Tamilnadu, India.
}

\section{To Cite this Article}

V Nanthagopal and Dr. S Chitra, "Power Quality Improvement Using Three-Phase Solar PV Integrated UPQC", International Journal for Modern Trends in Science and Technology, Vol. 06, Issue 07, July 2020, pp.:153-158; https://doi.org/10.46501/IJMTST060725

\section{Article Info}

Received on 12-June-2020, Revised on 30-June-2020, Accepted on 18-July-2020, Published on 24-July-2020.

\section{ABSTRACT}

This paper proposes the application of a Dynamic Voltage Restorer (DVR) to enhance the power quality and analyzed the solar PV integrated unified power quality conditioner ( $P V$-UPQC). The PV-UPQC is employed to maintain power quality under various current and voltage distortion. The PV-UPQC consists of a shunt and series compensators connected back to back with common DC-link. The shunt compensator performs the dual function of extracting power from $P V$ array apart from compensating for load current harmonics. The series compensator compensates for the grid side power quality problems such as grid voltage sag and swell. In proposed system Dynamic Voltage Restorer (DVR) is used as a series compensator and also it enhance the power quality. The UPQC is eliminate power quality issues like unbalanced grid voltage with harmonics and load harmonics. The performance of the system are evaluated by simulating in MATLAB/Simulink environment under a nonlinear load.

KEYWORDS:UPQC, Solar PV, Series compensator, Shunt compensator, DVR, PV-UPQC

Copyright (C) 2020 International Journal for Modern Trends in Science and Technology

DOI: https://doi.org/10.46501/IJMTST060725

\section{INTRODUCTION}

Now a days the requirement of electrical power generation is increased rapidly by satisfying the load demand. In electrical world with the increase in integration of renewable energy system such as solar energy and wind energy into modern distribution system owing to its benefits of being eco-friendly. With the increase in installation of renewable energy sources and nonlinear loads results in various power quality problems both at load side and grid side. Since renewable energy sources like solar energy and wind energy are increased used in distribution systems leads to power quality problems like voltage sags/swells, interruption, flicker and eventually instability in the grid. These power quality problems can also lead to frequent malfunctioning of power electronic systems and false triggering of electronic systems and also increased capacitor heating. Current quality issues are mainly caused by the nonlinear loads connected in the distribution systems. These nonlinear loads inject harmonics into distribution system.

Customer power devices such as distribution static compensator (DSTATCOM), dynamic voltage restorer (DVR), unified power quality conditioner (UPQC) are used to mitigate power quality problems caused by loads as well as to protect the sensitive loads from grid side voltage quality problems. Dynamic voltage restorer is a series connected power electronic system which 
compensates for the grid voltage sag/swells. The PV-UPQC consists of a shunt and series compensators connected back to back with common dc-link which combines functionality of both compensators. Dynamic voltage restorer is used as a series compensator and also it enhance the power quality.

Dynamic Voltage Restorer (DVR) has the ability to attenuate voltage disturbances. It is generally installed between the load and the source in the distribution system to provide rapid support of the voltage by injecting the required voltage in series with the mains voltage through an injection transformer. DVR to mitigate voltage disturbances, minimize their impact on the overall stability of the transmission and distribution network. Solar PV is used instead of using inverter which gives the dual benefits of clean energy generation.

Reference signal generation is a major task in control of PV-UPQC. Reference signal generation techniques can be broadly divided into two category time-domain and frequency domain techniques. Time domain techniques are commonly used because of lower computational requirements in real time implementation. The commonly used techniques include instantaneous reactive power theory, synchronous reference frame theory (d-q theory) and instantaneous symmetrical component theory cycle. The main advantages of the proposed system are as follows,

- Integration of clean energy generation and power quality improvement.

- Simultaneous voltage and current quality improvement.

- Stable under various dynamic conditions of voltage sag/swells, load unbalance and irradiation variation.

In this paper, the design and performance analysis of a three-phase solar PV integrated UPQC is presented. The dynamic performance of PV-UPQC is analyzed under conditions of grid voltage fluctuations and irradiation variations. The performance of the system is analyzed extensively under both dynamic and steady state conditions using MATLAB/Simulink software. The load used is a nonlinear load consisting of an uncontrolled bridge rectifier with a voltage fed load.

\section{SYSTEM CONFIGURATION}

The UPQC is the combination of series and shunt converter. The role of series inverter inject voltage in series with load voltage when source voltage become unbalanced. The series compensator inject or absorb voltage at the required magnitude and phase angle which can solve the problem of voltage sag/swell and flicker. The series inverter can also absorb or inject real power in addition to reactive power. The shunt converter has the ability to regulate the DC-link voltage and compensate the current related $\mathrm{PQ}$ issues such as harmonics, inter-harmonics and reactive power requirement.

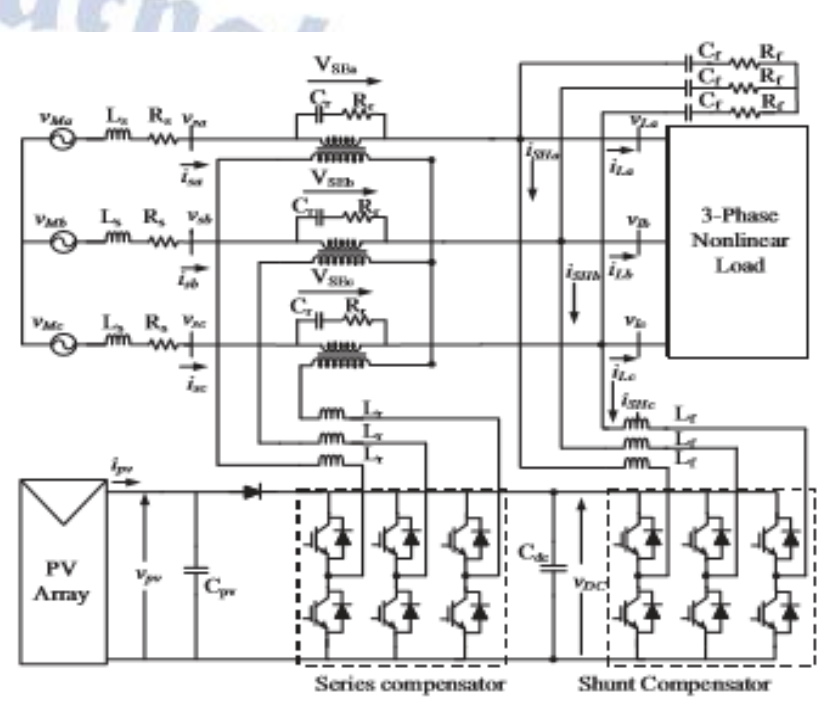

Fig.1 System Configuration of PV-UPQC

The structure of the PV-UPQC is shown in the fig. 1. The PV-UPQC is designed for a three-phase system. The PV-UPQC consists of shunt and series compensator connected with a common DC-bus. At load side, shunt compensator is connected to handle the current quality issues. The solar PV array is integrated to the DC-link of UPQC through a reverse blocking diode. The series compensator used to compensate the voltage which can reduce the voltage sag and swell. The shunt and series compensators are connected to the grid through interfacing inductors. A series compensator injects the voltage into the grid by using series injection transformer. Harmonics are generated by converters are eliminated by using filters. The load used is a nonlinear load consisting of the bridge rectifier with a voltage-fed load.

The design of PV-UPQC involves the appropriate sizing of PV array, DC-link capacitor, DC-link voltage level, etc. The rating of solar PV module used to realize PV array. The PV array is directly integrated to the DC-link of UPQC, the PV array is sized such that the maximum power point voltage is same as desired DC-link voltage. The rating is such that, under nominal conditions the PV array supplies a part of the load active power and 
remaining load active power is drawn from the grid. The characteristics of the PV array is shown in below.

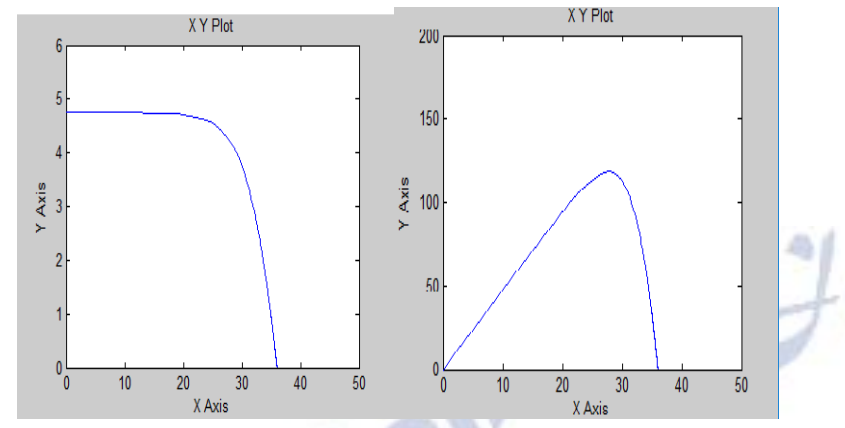

Fig.2 I-V and P-V Characteristics of PV

Fig. 2 shows the I-V and P-V characteristics of the PV module. From the figure the short circuit current of PV module is approximately $4.75 \mathrm{~A}$ and open circuit voltage is approximately $36 \mathrm{~V}$ and also the maximum power rating is approximately $130 \mathrm{~W}$. The design of PV-UPQC is further elaborated as follows.

\section{1) Selection of DC bus voltage}

The DC-link capacitor present in the PV-UPQC is common to shunt inverter, series inverter as well as solar PV array. The selection of DC-link voltage magnitude should be evaluated such that its value will be double the peak of phase voltage of the considered three-phase system. Therefore, $V_{d c}$ is presented as

$$
V_{d c}=\frac{2 \sqrt{2} V_{L}}{\sqrt{3} m}
$$

Where,

$V_{d c}-$ DC-link voltage

$m$ - Modulation index

$V_{L^{-}}$line voltage

\section{2) Interfacing inductor for series compensator}

The interfacing inductor rating of the series compensator depends upon the ripple current at swell condition, switching frequency and dc-link voltage. The expression for the interfacing inductor is as,

$L_{f}=\frac{\sqrt{3} \times m V_{d c} K_{S E}}{120 f_{s e} I_{r}}$

Where,

$V_{d c}-$ DC-link voltage

$m$ - Modulation index

$K_{S E}-$ Transformer turns ratio

$f_{s e}$ - Switching frequency

$I_{y}-$ Inductor current ripple
$L_{f}$ - Inductor of series compensator

\section{3) Series injection transformer}

The PV-UPQC is designed to compensate for a sag/swell. Hence, the required voltage to be

injection which results in low modulation index for the series compensator whose DC link voltage. In order to operate the series compensator with minimum harmonics, one keeps modulation index of series compensator near to unity. Hence a series transformer is used with a turn's ratio,

$K_{S E}=\frac{V_{V S C}}{V_{S E}}$

Where,

$K_{S E}-$ Transformer turns ratio

$V_{V S C}$ - Voltage of voltage source converter

$V_{S E}-$ Voltage of series injection transformer

\section{DYNAMIC VOLTAGE RESTORER}

The main role of the DVR is to balance and regulate the voltage and prevent harmonics from the source voltage to reach the load. The DVR provides series compensation. It consists of a voltage source inverter in series with the supply line that helps in achievement of a particular load voltage.

\section{Principle and operation of DVR}

A DVR is a solid-state power electronics switching device which comprises of either GTO or MOSFET, a capacitor bank as energy storage device and injection transformers. The DVR is connected in between the distribution system and the load. The term of DVR is that by means of an injecting transformer a control voltage is generated by a forced commuted convertor which is in series to the bus voltage. A regulated DC voltage source is provided by a DC capacitor bank which acts an energy storage device are shown in fig. 3.

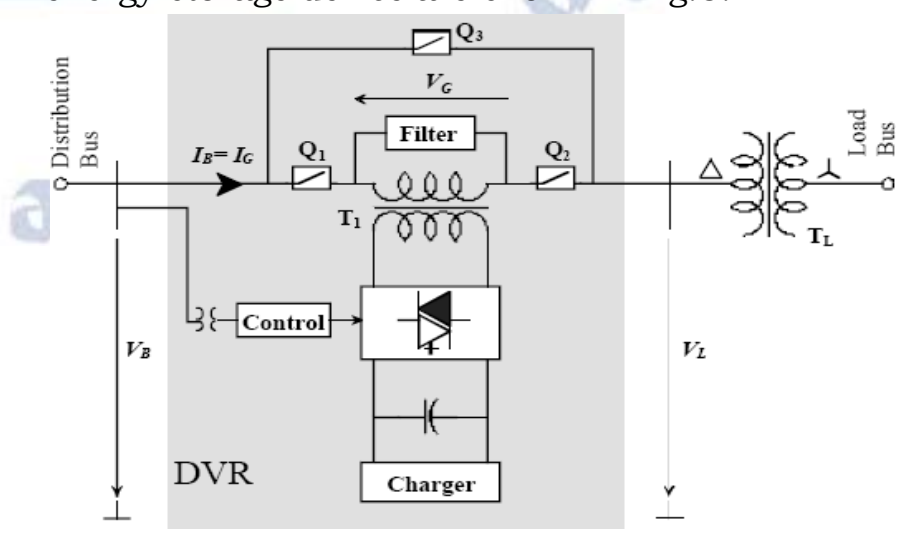

Fig.3 Principle of Dynamic Voltage Restorer 
Under normal operating conditions when there is no voltage sad and DVR provides very less magnitude of voltage to compensate for the voltage drop of transformer and device losses. But when there is a voltage harmonics in the distribution system. The DVR will be generate a required controlled voltage of high magnitude and desired phase angle which ensures that load voltage is uninterrupted and it is maintained. In this case the capacitor will be discharged to keep the load supply constantly. The DVR is capable of generating or absorbing reactive power but the reactive power injection of the device must be provided by an external energy source or energy storage system.

\section{Construction of DVR}

Power circuit and control circuit are the two main parts of the DVR. There are various critical parameters of control signals are such as magnitude, phase shift, frequency, etc. Which are injected by DVR. These parameters are derived by the control circuit. The injected voltage is generated by the switches in the power circuit based on the control signals. Furthermore, the basic structure of the DVR is described by power circuit is discussed. The power circuit is shown in the fig. 4. The DVR to mitigate voltage disturbances, minimize their impact on overall stability of the transmission and distribution network.

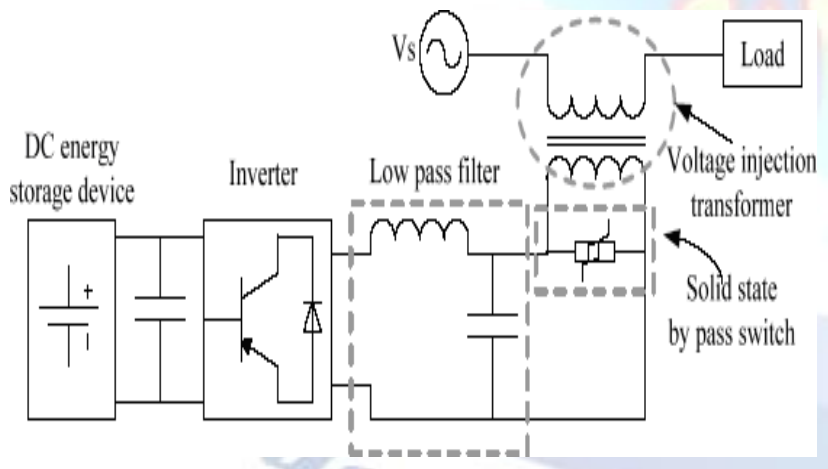

Fig.4 Power Circuit of DVR

The main role of the DVR is to balance and regulate the voltage and prevent harmonics from the source voltage to reach the load. The basic structure of the Dynamic Voltage Restorer (DVR) consists of

1) Injection transformer

2) Harmonic filter

3) Energy storage device

4) VSC

5) DC charging circuit

6) Control system
DVR has the ability to attenuate voltage disturbances. It is generally installed between the load and the source in the distribution system to provide rapid support of the voltage by injecting the required voltage in series with the main voltage through an injection transformer by the energy storage device is a key factor, as it decides the compensation ability of DVR.

\section{CONTROL STRATEGY}

The main subsystems of PV-UPQC are the shunt compensator and the series compensator. The shunt compensator compensates for the load power quality problems such as load current harmonics and load reactive power. In case of PV-UPQC, the shunt compensator performs the additional function of supplying power from the solar PV array.

The series compensator protects the load from the grid side power quality problems such as sags/swells by injecting appropriate voltage in phase with grid voltage. The control strategy for the series compensator are pre-sag compensation, in-phase compensator injects voltage in same phase as that of grid voltage, which results in minimum injection voltage by the series compensator. The control structure of the series compensator is shown in fig.5. Reference signal generation is a major task in control of PV-UPQC. Reference signal generation techniques can be broadly divided into time-domain and frequency domain techniques. Time domain techniques are commonly used because of lower computational requirements in real-time implementation. The commonly used techniques include instantaneous reactive power theory ( $\mathrm{p}-\mathrm{q}$ theory), synchronous reference frame theory (d-q theory) and instantaneous symmetrical component theory.

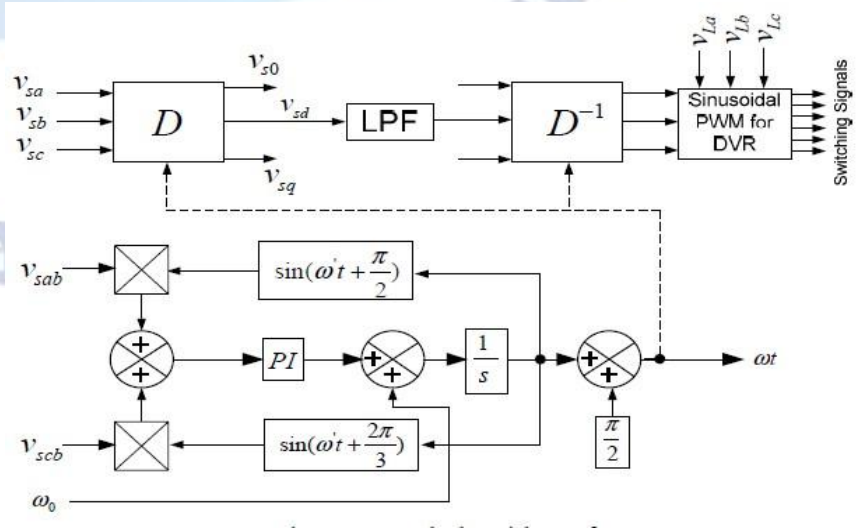

Fig.5 Control Algorithm of DVR 
The main issue in use of synchronous reference frame theory based method is that during load unbalanced condition, double harmonic component is present in the d-axis current. Due to this, low pass filters with very low cut off frequency is used to filter out double harmonic component. This results in poor dynamic performance. In this work, a moving average filter (MAF) is used to filter the d-axis current to obtain fundamental load active current. This gives optimal attenuation and without reducing the bandwidth of the controller. Recently, MAF has been applied in improving performance of DC-link controllers as well as for grid synchronization using improved phase locked loop (PLL).

The fundamental component of grid voltage is extracted using a PLL which is used for generating the reference axis in dqo domain. The reference load voltage is generated using the phase and frequency information of grid voltage obtained. The grid voltages, load voltages and reference load voltages are converted into d-q-o domain. The error between the reference load voltage and load voltage gives the series compensator voltage reference. The error between the load voltage and grid voltage gives actual voltage series compensator voltage. The difference between reference and actual series compensator voltages is passed to PI controllers to generate appropriate reference signals. These signals are converted to abc domain and passed through pulse width modulation (PWM) voltage controller to generate appropriate gating signals for the series compensator.

\section{RESULTS AND DISCUSSION}

The performance of solar PV integrated Unified Power Quality Conditioner (UPQC) is analyzed and evaluated in the various conditions that is discussed in this section. The system PV-UPQC is consists of series compensator and shunt compensator that are simulated through MATLAB/Simulink software. The load is used asa nonlinear load consisting of three phase diode bridge rectifier with R-L load. The FFT analysis are also discussed in this section. The results are obtained and discussed in given below. Fig. 6 shows the waveform of source voltage and source current during the non-linear load condition. These waveforms are given to the input of the controller. The controller is to eliminate or minimize the harmonics, errors, sag and swells in the source voltage and source current.
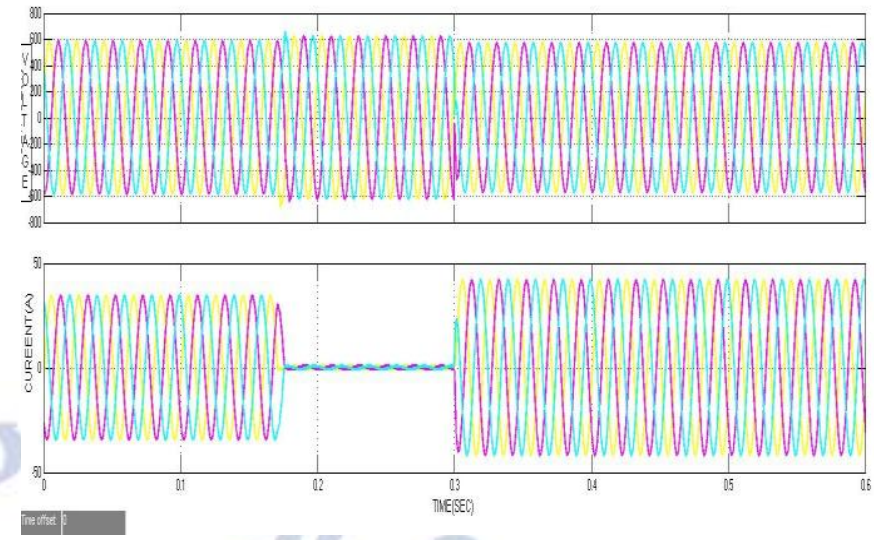

\section{Fig.6 Source Voltage and Current Waveform}

Fig.7 shows the PI Controller output load voltage and load current waveforms. By using PI controller the harmonics distortion is minimized.

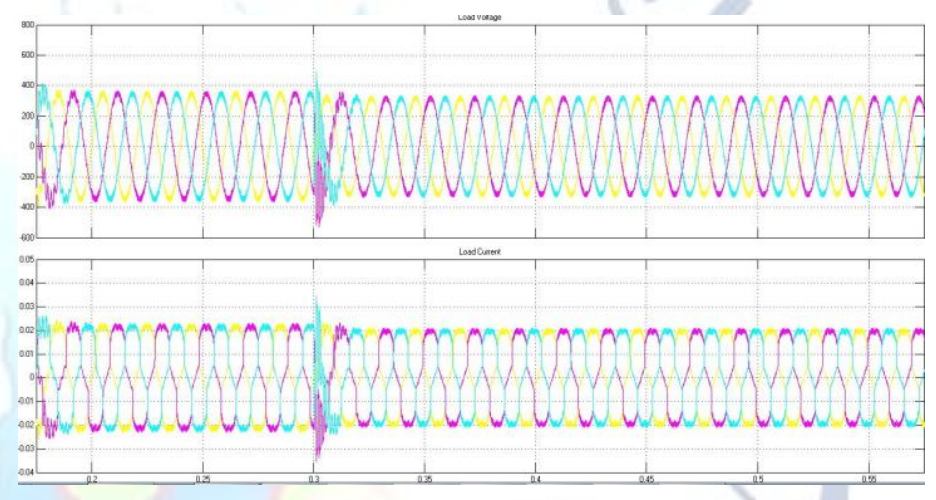

\section{Fig.7 Load Voltage and Current Waveform of PI Controller}

By using PI controller load voltage and current are analyzed the FFT analysis to find the Total Harmonic Distortion (THD). The harmonics are reduced with help of PI controller the THD value is $11.73 \%$. That FFT analysis is shown in fig.8.

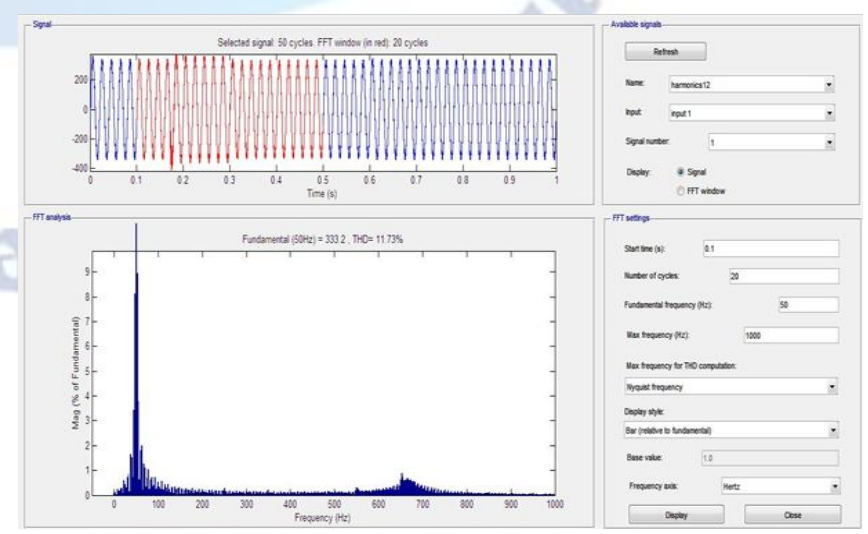

Fig.8 FFT Analysis of PI controller 
The fig.9 shows the output waveform of load voltage and load current of SRF controller. By using SRF controller the harmonics is minimized compared to PI controller.
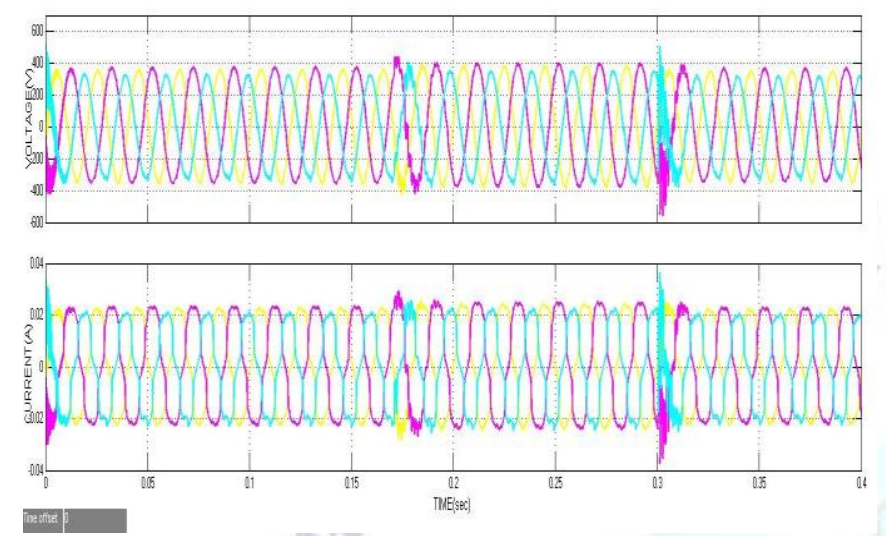

\section{Fig.9 Output Waveform of Load Voltage and Current of SRF Controller}

The fig. 10 represented the FFT Analysis of SRF controller and also it shows the THD value. The THD value of SRF controller is $4.22 \%$. The SRF controller is minimized the harmonics compared to PI controller the THD value is minimized.

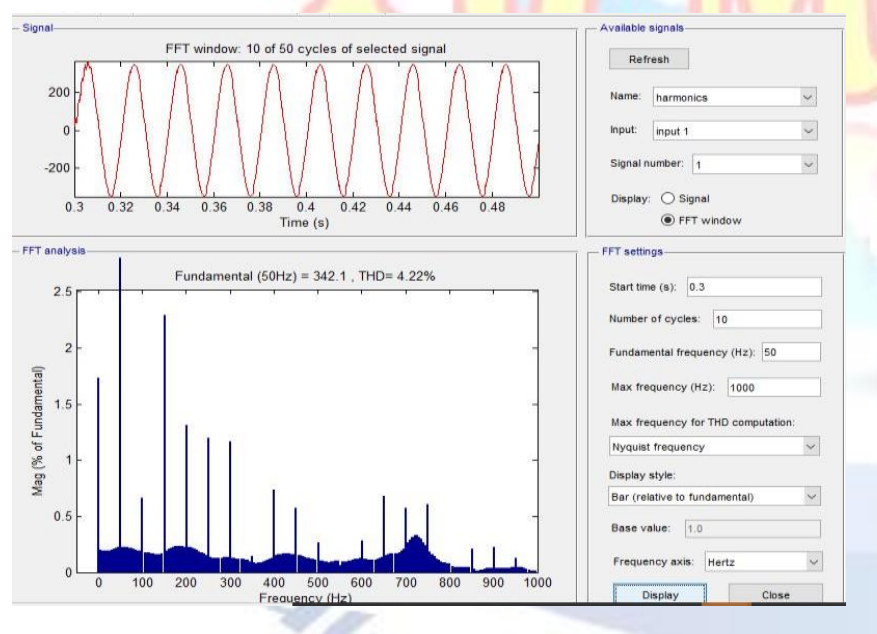

Fig.10 FFT Analysis of SRF Controller

\section{CONCLUSION}

In this work modelling and simulation of UPQC with necessary control strategy is discussed and implemented. The simulation results showed clearly the performance of the UPQC in mitigating the voltage sag and swell. In this project, synchronous reference frame (SRF) theory based control method is implemented to control the working of unified power quality conditioner based dynamic voltage restorer (DVR). The performance of the system is evaluated by simulating in the MATLAB/Simulink using non-linear load. The $\%$ THD is reduced in the proposed method at grid side. The system is noticed to be stable and load voltage is maintained at desired level even under non-linear load condition.

\section{REFERENCES}

[1] Chellali Benacaiba, Brahim Ferdi, "Voltage Quality Improvement Using DVR" Electrical Power Quality and Utilisation, vol.11, 2008

[2] B. Singh, A. Chandra and K.A Haddad, Power Quality: Problems and mitigation Techniques. London: wiley, 2015.

[3] Basu, Das, Dubey, "Comparative evaluation of two models of UPQC for suitable interface to enhance power quality" Electric Power System Research, vol.77, pp.821-830, 2007.

[4] X.Zhang, Q.Wang, "Unified Power Quality Conditioner with Model Predictive Control" International conference of computer science education, 2010, pp. 1239-1244.

[5] Yash Pal, A.Swarup, Bhim Singh, "A Control strategy based on UTT and Icos $\Phi$ theory of three-phase, four wire UPQC for power quality improvement" International journal of engineering, science and technology, vol.3,, 2011.

[6] V. Khadkikar, P.Agarwal, "A simple new control technique for Unified Power Quality Conditioner (UPQC), "IEEE International conference on harmonics and quality of power, 2004.

[7] Mehmet Ucar and Engin Ozdemir, "Control of a 3-phase 4-leg active power filter under non-ideal mains voltage condition" Electrical Power Research, vol.78, 2008.

[8] F. Kamran and T.G. Habetler, "Combined deadbeat control of a series parallel converter combination used as a universal power filter" Power electronics conference, vol.1, 1995.

[9] Y.Yang,P.Enjeti,"Wide-scale adoption of photovoltaic energy: grid code modifications are explored in the distribution grid" IEEE, vol.21, pp. 21-31, 2015. 